\title{
Disparities in Patient-Reported Interest in Web-Based Patient Portals: Survey at an Urban Academic Safety-Net Hospital
}

Shobha Sadasivaiah ${ }^{1}, \mathrm{MD}, \mathrm{MPH}$; Courtney R Lyles $^{2}$, PhD; Stephen Kiyoi ${ }^{1}$, MLIS, MS HAIL, AHIP; Piera Wong ${ }^{3}$, RN, MS, AOCNS; Neda Ratanawongsa², MD, MPH

\footnotetext{
${ }^{1}$ Zuckerberg San Francisco General Hospital and Trauma Center, University of California San Francisco, San Francisco, CA, United States

${ }^{2}$ Zuckerberg San Francisco General Hospital and Trauma Center, UCSF Center for Vulnerable Populations, University of California San Francisco, San Francisco, CA, United States

${ }^{3}$ Zuckerberg San Francisco General Hospital and Trauma Center, San Francisco Department of Public Health, San Francisco, CA, United States
}

\section{Corresponding Author:}

Shobha Sadasivaiah, MD, MPH

Zuckerberg San Francisco General Hospital and Trauma Center

University of California San Francisco

1001 Potrero Avenue

San Francisco, CA,

United States

Phone: 14152062951

Fax: 14152064882

Email: shobha.sadasivaiah@ucsf.edu

\begin{abstract}
Background: Offering hospitalized patients' enrollment into a health system's patient portal may improve patient experience and engagement throughout the care continuum, especially across care transitions, but this process is less studied than portal engagement in the ambulatory setting. Patient portal disparities exist and may lead to differences in access or outcomes. As such, it is important to study upstream factors in a typical hospital workflow that could lead to those disparities in safety-net settings.

Objective: The objective of this study was to evaluate sociodemographic characteristics associated with interest in a health care system's portal among hospitalized patients and reasons for no interest.

Methods: Nurses assessed interest in a Web-based patient portal, expressed by the patient as "yes" or "no," as part of the admission nursing assessment among patients at an academic urban safety-net hospital and recorded responses in the electronic health record (EHR), including reasons for no interest. We extracted patient responses from the EHR.

Results: Among 23,994 hospitalizations over a 2-year period, 35.90\% (8614/23,994) reported an interest in a Web-based portal. Reasons for no interest included the following: not interested/other reason $41.68 \%(6410 / 15,380)$, no ability to use/access computers/internet $29.59 \%$ (4551/15,380), doesn't speak English 11.15\% (1715/15,380), physically or mentally unable $8.70 \%$ (1338/15,380), does not want to say $8.70 \%$ (1338/15,380), security concerns $0.03 \%(4 / 15,380)$, and not useful $0.16 \%(24 / 15,380)$. Among the 16,507 unique patients included in this sample, portal interest was lower in older, African American, non-English speaking, and homeless patient populations.

Conclusions: In a safety-net system, patient interest at the time of hospitalization in a Web-based enterprise portal-a required step before enrollment-is low with significant disparities by sociodemographic characteristics. To avoid worsening the digital divide, new strategies are needed and should be embedded within routine workflows to engage vulnerable safety-net patients in the use of Web-based health technologies.
\end{abstract}

(J Med Internet Res 2019;21(3):e11421) doi: 10.2196/11421

\section{KEYWORDS}

patient portals; vulnerable populations; health care disparities; safety net hospitals; health information technology 


\section{Introduction}

\section{Background}

Patient portals are websites that offer access to personal health information on the Web, such as test results, medical histories, immunization histories, and secure messaging with providers. Health care systems-leveraging federal incentives for meaningful use of electronic health records (EHRs) - are promoting patient portals to improve quality and safety, engagement, and care coordination with a goal of improved patient outcomes. Although the evidence is mixed about the benefits to health outcomes [1], portals have been associated with improvement in patients' diabetes medication adherence [2], understanding of medical conditions [3], and retention in a health care system [4].

Demographic factors such as age and education affect patient interest and use of patient portals [5]. Ambulatory and inpatient research suggests racial and ethnic disparities in portal use [6,7]. However, early research shows that diverse patients from safety-net health care settings have high interest in portal features such as electronic communication with providers [8], suggesting an opportunity for intervention.

Safety-net health care systems, systems that care for vulnerable, uninsured, or predominantly Medicaid patient populations, may face additional challenges engaging patients in their portals. For patients in safety-net settings, health care systems must be able to assess interest in enrollment, including frequently explaining to patients what a portal is and how portals may be useful for their care across the care continuum. Although portals have traditionally been studied across ambulatory settings [6], enrollment in a health care organization's portal during a hospital admission represents an opportunity to engage high-risk patients in their health. By providing patients information about their hospital course and recommendations for treatment and follow-up care, a health care system portal may help improve a patient's postdischarge self-care, transitions to ambulatory care, and ultimately improve health outcomes.

\section{Objectives}

No study has systematically assessed interest in a health network's portal within a typical hospital workflow among hospitalized urban safety-net patients. This study examined the interest in an enterprise-wide Web-based portal reported by hospitalized patients, how interest varied by sociodemographic characteristics, and the barriers among those declining portal interest.

\section{Methods}

\section{Overview}

This cross-sectional study evaluated hospitalized patients' interest in enrolling in a health care system's portal at an urban academic safety-net hospital. The patient portal offered information about the hospitalization (hospital after-visit summary with discharge instructions, summary of hospital course, and test results), as well as ambulatory patient portal content (primary and specialty care after-visit summaries, medications, allergies, problem lists, test results, and secure messaging with primary care providers). Eligible patients included adults (aged 18 years and over) admitted to acute medical, surgical, or gynecologic obstetric units over a 2-year period (September 2015-September 2017). This sample excludes patients under 18 years of age, admitted to skilled nursing or psychiatric units or reporting existing portal accounts.

\section{Patient Assessment}

Nursing leadership provided universal education to bedside nurses about the content and value of the patient portal and how to assess interest using an EHR-built admission assessment question stem (Are you interested in learning more about or signing up for our free, secure website to view your health record online? The website gives you access to your lab results, medication lists, discharge instructions, and other information from your stay). Nurses could record patient interest as yes or no, followed by a structured drop-down menu based on existing literature about portal barriers [9,10]: no ability to use/access computers/internet, doesn't speak English, physically or mentally unable, not interested/other reason, doesn't way to say, or nurses could write over a free- text reason. By incorporating this assessment into routine clinical operations, nursing leadership standardized the verbiage of the assessment, but nurses could individualize any clarifying questions or follow-up counseling about the portal. Nurses did not offer specific technology or portal demonstrations.

The data for this analysis were abstracted from the EHR nursing assessments as well as the EHR sociodemographic section (age, gender, race/ethnicity, language, insurance type, and homelessness).

\section{Analysis}

The primary outcome was the proportion of patients with portal interest recorded as yes during at least one admission. As some patients may change their responses in subsequent admissions, we also calculated the proportion of portal interest expressed at the hospitalization level and calculated the proportion of reasons for $\mathrm{No}$ interest during each hospitalization, coding free-text reasons into the existing or separate categories.

We then used logistic regression with measured sociodemographic covariates to calculate the unadjusted and adjusted odds of portal interest during at least one admission. Statistical analysis was performed using Stata version 15.1 (StataCorp). The University of California San Francisco Institutional Review Board approved this study.

\section{Results}

\section{Demographics}

Among 16,507 unique patients, the average age was 53 years (SD 19.17): $42.16 \%(6960 / 16,507)$ were women, $26.43 \%$ $(4362 / 16,507)$ white, $28.02 \%(4625 / 16,507)$ Hispanic, $18.56 \%$ (3063/16,507) African American, 19.06\% (3147/16,507) Asian, $7.93 \%(1309 / 16,507)$ other. Furthermore, $49.35 \%(8146 / 16,507)$ preferred a non-English language--10.67\% (1761/16,507) Spanish and $5.40 \% \quad(892 / 16,507)$ Chinese. $80.50 \%$ $(13,288 / 16,507)$ had Medicaid or Medicare, and $14.17 \%$ 
$(2339 / 16,507)$ reported homelessness. There was an average of 1.4 admissions per patient in this cohort during the period studied (see Table 1).

\section{Reasons for Lack of Portal Interest}

When analyzed across 23,995 admissions, patients reported interest in the portal during $35.90 \%(8614 / 23,994)$ of admissions. The most commonly documented reasons for no were the following: not interested $41.68 \%$ (6410/15,380), no ability to use/access computers/internet $29.59 \%$ (4551/15,380), doesn't speak English 11.15\% (1715/15,380), physically or mentally unable $8.70 \%(1338 / 15,380)$, does not want to say $8.70 \%$ (1338/15,380), security concerns $0.03 \%(4 / 15,380)$, not useful $0.16 \%(24 / 15,380)$.

Table 1. Demographic characteristics of adults asked about portal interest during admissions to an urban academic safety-net hospital between September 2015 and September 2017.

\begin{tabular}{|c|c|}
\hline Patient Characteristics $(\mathrm{N}=16,507)$ & Statistics \\
\hline Age (years), mean (SD) & $53.06(19.17)$ \\
\hline Women, n (\%) & $6960(42.16)$ \\
\hline \multicolumn{2}{|l|}{ Self-reported race/ethnicity, n (\%) } \\
\hline White & $4362(26.43)$ \\
\hline Hispanic & $4625(28.02)$ \\
\hline African American/black & $3063(18.56)$ \\
\hline Asian & $3147(19.06)$ \\
\hline Native Hawaiian/Pacific Islander & $222(1.34)$ \\
\hline American Indian/Alaskan Native & $120(0.73)$ \\
\hline Other/mixed & $967(5.86)$ \\
\hline \multicolumn{2}{|l|}{ Primary language, $\mathrm{n}(\%)$} \\
\hline English & $8361(50.65)$ \\
\hline Spanish & $1761(10.67)$ \\
\hline Cantonese, Mandarin, or Toishanese & $892(5.40)$ \\
\hline Other Asian languages, $\mathrm{n}(\%)$ & $208(1.26)$ \\
\hline Other, $\mathrm{n}(\%)$ & $5285(32.02)$ \\
\hline \multicolumn{2}{|l|}{ Insurance, n (\%) } \\
\hline Medicaid or county health plan for uninsured ${ }^{\mathrm{a}}$ & $8278(50.15)$ \\
\hline Medicare & $5010(30.35)$ \\
\hline Commercial insurance & $1300(7.88)$ \\
\hline Other insurance & $1919(11.63)$ \\
\hline \multicolumn{2}{|l|}{ Homeless status } \\
\hline Yes $^{\mathrm{b}}, \mathrm{n}(\%)$ & $2339(14.17)$ \\
\hline No, n $(\%)$ & $12478(75.59)$ \\
\hline Unknown, n (\%) & $1690(10.24)$ \\
\hline Admissions, mean (range) & $1.4(1-33)$ \\
\hline
\end{tabular}

${ }^{\mathrm{a}}$ These health care access programs (administered by the county Medicaid managed care organization) provide medical services for uninsured county residents (aged 18-64 years) or adults who provide county-supported in-home support services.

${ }^{\mathrm{b}}$ Patients reported yes during at least one admission. 
Figure 1. Patient interest in an online healthcare system portal during at least one admission to an academic safety net hospital ( $\mathrm{n}=16507$ patients, September 2015-September 2017).

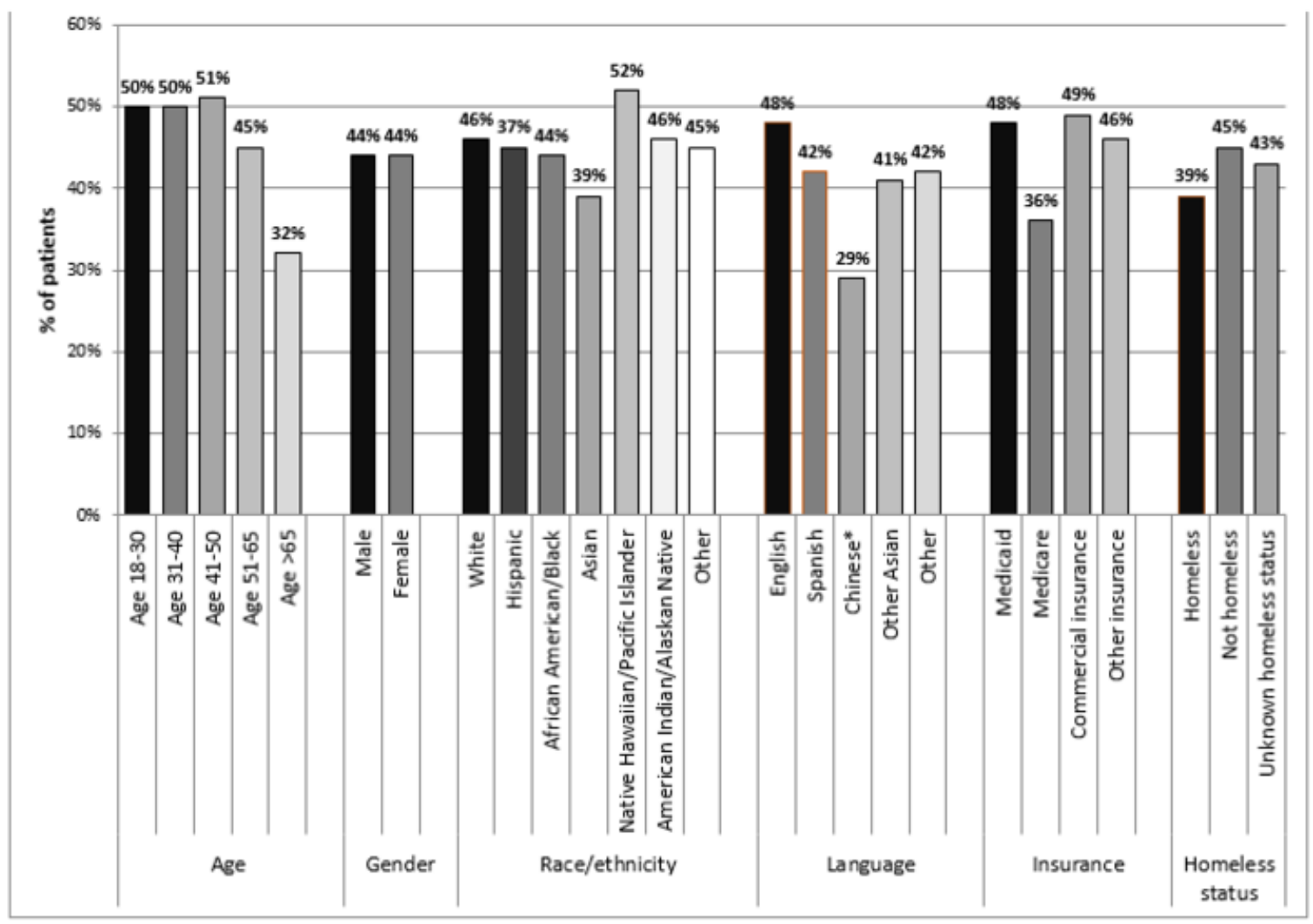

- Cantonese, Mandarin, Toishanese

\section{Interest by Sociodemographic Characteristic}

However, $44 \%$ of unique patients reported interest in the patient portal during at least one admission. Figure 1 shows unadjusted proportions of interest in the portal during at least one admission, stratified across sociodemographic characteristics. In unadjusted analyses (Table 2), the odds of expressing interest in the Web-based portal were significantly lower for patients in the 50 to 65 years age group (adjusted odds ratio [AOR] 0.82, 95\% CI $0.74-0.90$ vs $18-29$ age group), the greater than 65 years of age group (AOR $0.47,95 \%$ CI $0.42-0.52$ vs $18-29$ age group), Asians (AOR $0.76, \quad 95 \%$ CI $0.69-0.84$ vs white), Spanish-speaking (AOR 0.78, 95\% CI 0.70-0.86 vs English),
Chinese-speaking (AOR 0.46, 95\% CI 0.39-0.53 vs English), patients on Medicare (AOR 0.60, 95\% CI 0.56-0.65 vs Medicaid), and patients reporting homelessness (AOR $0.7795 \%$ CI 0.70-0.84 vs not homeless).

In adjusted models (Table 2), older age (AOR 0.85, 95\% CI $0.77-0.95$ for $>50$ and AOR $0.50,95 \%$ CI $0.44-0.57$ for $>65$ vs 18-29), African American race (AOR 0.87, 95\% CI 0.79-0.96 vs white), Spanish or Chinese languages (AOR 0.69, 95\% CI 0.61-0.78 and AOR 0.54, 95\% CI 0.46-0.65 vs English), and homelessness (AOR 0.60, 95\% CI 0.54-0.66 vs housed) were significantly associated with No portal interest during any hospitalization. 
Table 2. Odds of expressing interest in a patient portal among patients at an urban academic safety-net hospital ( $\mathrm{n}=16,507$ unique patients).

\begin{tabular}{|c|c|c|c|c|}
\hline Sociodemographic characteristic & Unadjusted odds ratio & $P$ value & Adjusted odds ratio ${ }^{a}$ & $P$ value \\
\hline \multicolumn{5}{|l|}{ Gender } \\
\hline Male & Ref & $-\mathrm{b}$ & $\operatorname{Ref}^{c}$ & - \\
\hline Female & 1.01 & 0.85 & 1.04 & 0.25 \\
\hline \multicolumn{5}{|l|}{ Age (years) } \\
\hline $18-29$ & Ref & - & Ref & - \\
\hline $30-39$ & 0.99 & 0.91 & 1.01 & 0.9 \\
\hline $40-49$ & 1.04 & 0.49 & 1.09 & 0.15 \\
\hline $50-65$ & 0.82 & $<.001$ & 0.85 & 0.003 \\
\hline$>65$ & 0.47 & $<.001$ & 0.5 & $<.001$ \\
\hline \multicolumn{5}{|l|}{ Race or ethnicity } \\
\hline White & Ref & - & Ref & - \\
\hline Hispanic & 0.98 & 0.65 & 0.93 & 0.15 \\
\hline African American & 0.95 & 0.24 & 0.87 & 0.01 \\
\hline Asian & 0.76 & $<.001$ & 0.91 & 0.1 \\
\hline Native Hawaiian/Pacific Islander & 1.31 & 0.05 & 1.09 & 0.52 \\
\hline American Indian/Alaskan Native & 1.01 & 0.95 & 0.94 & 0.74 \\
\hline Other & 1 & 0.96 & 0.92 & 0.24 \\
\hline \multicolumn{5}{|l|}{ Language } \\
\hline English & Ref & - & Ref & - \\
\hline Spanish & 0.78 & $<.001$ & 0.69 & $<.001$ \\
\hline Cantonese, Mandarin, or Toishanese & 0.46 & $<.001$ & 0.54 & $<.001$ \\
\hline Other Asian & 0.77 & 0.07 & 0.9 & 0.47 \\
\hline Other & 0.78 & $<.001$ & 0.78 & $<.001$ \\
\hline \multicolumn{5}{|l|}{ Insurance } \\
\hline Medicaid & Ref & - & Ref & - \\
\hline Medicare & 0.6 & $<.001$ & 0.91 & 0.07 \\
\hline Commercial insurance & 1.03 & 0.64 & 0.94 & 0.34 \\
\hline Other insurance & 0.94 & 0.2 & 0.98 & 0.71 \\
\hline \multicolumn{5}{|l|}{ Homeless status } \\
\hline Not homeless & Ref & - & Ref & - \\
\hline Homeless & 0.77 & $<.001$ & 0.6 & $<.001$ \\
\hline Unknown homeless status & 0.91 & 0.07 & 0.85 & 0.003 \\
\hline
\end{tabular}

${ }^{\mathrm{a}}$ Logistic regression adjusted for all the variable listed in the table.

${ }^{\mathrm{b}}$ Not applicable.

${ }^{\mathrm{c}}$ Ref: reference value.

\section{Discussion}

\section{Conclusions}

Fewer than half of the patients admitted to a safety-net hospital were documented by nurses as interested in the patient portal during at least one of their admissions to a safety-net hospital, with significantly lower odds of portal interest among older, nonwhite, non-English-speaking, and homeless patients. This is the first attempt at universally quantifying how many hospitalized patients are interested in a health care system's portal and highlighting the prevalence of patient barriers to portal engagement within a safety-net setting.

A notable finding from this analysis was that the proportion of hospitalizations during which patients expressed portal interest (31\%) was lower than the proportion of patients expressing portal interest during at least one hospitalization (44\%), a finding 
that remained true across sociodemographic categories. This finding suggests that offering the patient portal to a patient who has previously declined may be useful for subsequent engagement. Organizational, technical, or workflow protocols that fail to offer portal enrollment to patients who previously declined may exacerbate disparities. In safety-net systems, the simple intervention of standardizing offers with every hospitalization may be an important tool for engaging patients in these technologies.

Most hospitals - particularly safety-net hospitals with limited resources-may rely on their existing staff to engage patients in their portal. This paper reveals what may naturally happen in a typical workflow where engagement happens universally as a required part of admission. A strength of this study is that the nursing staff were essential partners and allies for portal promotion given their role in providing direct clinical care; this study was driven strongly by nursing leadership. As portal interest screening was incorporated as a required component of the initial admission nursing assessment, this study allowed us to capture sufficient data to understand demographic characteristics associated with portal use.

\section{Limitations}

Nonetheless, there are limitations to nurses alone as the only source of assessing patient interest, with potential bias in interpreting patients' reasons for no interest. In addition, the time of admission may not be the best time during the course of a patient's hospitalization to make this type of assessment depending on the acuity of a patient's condition. Although this study did not assess portal enrollment or use, the results highlight potential disparities in a necessary and required upstream process.

\section{Future Directions}

Although Web-based portals have historically been associated with ambulatory care services, interest and research on their use for hospitalized patients are rising. Acute care portals that provide patients with health care information and communication with their teams during hospitalization have been studied for usability [11,12], implementation [13,14], and association with readmission rates [15]. Incorporating acute care portal functionality into a health care system portal may increase interest among hospitalized patients in using a platform that crosses a system's health care settings, and further research on acute care portal design and implementation is needed. However, our findings suggest that the period of hospitalization also offers an opportunity to engage patients in a health care system portal that lacks acute care functionality. Indeed, after discharge, patients and their loved ones may have greater energy and capacity for understanding the hospital course and discharge instructions; access to this information may facilitate their ability to communicate important information to their ambulatory care providers.

This study is the first to begin to understand issues around portal use among inpatients, specifically in a safety-net setting. Research suggests that vulnerable populations need significant support to register and use a portal website $[16,17]$. Safety-net hospitals may have significant workflow challenges with providing portal education and support tailored to patients' language, literacy, vision/hearing, and other needs. These findings triggered local quality improvement initiatives that could be replicated elsewhere: portal and internet education coordinated by the hospital library, in-person and phone technical support for patients, a Web-based curriculum to teach skills in accessing and navigating the portal, and promotional materials about designating a caregiver proxy in our 5 key languages. Future research and policies to incentivize health information technology should incorporate strategies for tailoring patient portal usability and implementation for diverse populations to avoid worsening the digital divide.

\section{Acknowledgments}

Each author has participated sufficiently in the work to take public responsibility for appropriate portions of the content. SS takes responsibility for the integrity of the work as a whole, from inception to publication. Authorship credit was based only on (1) substantial contributions to conception and design or acquisition of data or analysis and interpretation of data and (2) drafting the article or revising it critically for important intellectual content. This study was funded by AHRQ Grants R00HS022408, 1K08HS022561, and P30HS023558, National Library of Medicine Grant G08 NLM012166, and it received funding from the Gordon and Betty Moore Foundation. The funders did not play any role in the review or approval of the manuscript for publication. Publication made possible in part by support from the University of California San Francisco Open Access Publishing Fund.

\section{Conflicts of Interest}

None declared.

\section{References}

1. Ammenwerth E, Schnell-Inderst P, Hoerbst A. The impact of electronic patient portals on patient care: a systematic review of controlled trials. J Med Internet Res 2012 Nov 26;14(6):e162 [FREE Full text] [doi: 10.2196/jmir.2238] [Medline: 23183044]

2. Lyles CR, Sarkar U, Schillinger D, Ralston JD, Allen JY, Nguyen R, et al. Refilling medications through an online patient portal: consistent improvements in adherence across racial/ethnic groups. J Am Med Inform Assoc 2016 Apr;23(e1):e28-e33 [FREE Full text] [doi: 10.1093/jamia/ocv126] [Medline: 26335983] 
3. Turvey C, Klein D, Fix G, Hogan TP, Woods S, Simon SR, et al. Blue Button use by patients to access and share health record information using the Department of Veterans Affairs' online patient portal. J Am Med Inform Assoc 2014;21(4):657-663. [doi: 10.1136/amiajnl-2014-002723] [Medline: 24740865]

4. Turley M, Garrido T, Lowenthal A, Zhou YY. Association between personal health record enrollment and patient loyalty. Am J Manag Care 2012 Jul 1;18(7):e248-e253 [FREE Full text] [Medline: 22823553]

5. Irizarry T, DeVito DA, Curran CR. Patient portals and patient engagement: a state of the science review. J Med Internet Res 2015;17(6):e148 [FREE Full text] [doi: 10.2196/jmir.4255] [Medline: 26104044]

6. Wallace LS, Angier H, Huguet N, Gaudino JA, Krist A, Dearing M, et al. Patterns of electronic portal use among vulnerable patients in a nationwide practice-based research network: from the OCHIN Practice-based Research Network (PBRN). J Am Board Fam Med 2016 Oct;29(5):592-603 [FREE Full text] [doi: 10.3122/jabfm.2016.05.160046] [Medline: 27613792]

7. Robinson JR, Davis SE, Cronin RM, Jackson GP. Use of a patient portal during hospital admissions to surgical services. AMIA Annu Symp Proc 2016;2016:1967-1976 [FREE Full text] [Medline: 28269956]

8. Schickedanz A, Huang D, Lopez A, Cheung E, Lyles CR, Bodenheimer T, et al. Access, interest, and attitudes toward electronic communication for health care among patients in the medical safety net. J Gen Intern Med 2013 Jul;28(7):914-920 [FREE Full text] [doi: 10.1007/s11606-012-2329-5] [Medline: 23423453]

9. Lyles CR, Harris LT, Jordan L, Grothaus L, Wehnes L, Reid RJ, et al. Patient race/ethnicity and shared medical record use among diabetes patients. Med Care 2012 May;50(5):434-440. [doi: 10.1097/MLR.0b013e318249d81b] [Medline: 22354209]

10. Lyles CR, Allen JY, Poole D, Tieu L, Kanter MH, Garrido T. "I Want to Keep the Personal Relationship With My Doctor": understanding barriers to portal use among African Americans and Latinos. J Med Internet Res 2016 Dec 3;18(10):e263 [FREE Full text] [doi: 10.2196/jmir.5910] [Medline: 27697748]

11. Walker DM, Menser T, Yen P, McAlearney AS. Optimizing the user experience: identifying opportunities to improve use of an inpatient portal. Appl Clin Inform 2018 Dec;9(1):105-113. [doi: 10.1055/s-0037-1621732] [Medline: 29444536]

12. Kelly MM, Coller RJ, Hoonakker PL. Inpatient portals for hospitalized patients and caregivers: a systematic review. J Hosp Med 2018 Dec 1;13(6):405-412. [doi: 10.12788/jhm.2894] [Medline: 29261819]

13. Grossman LV, Choi SW, Collins S, Dykes PC, O'Leary KJ, Rizer M, et al. Implementation of acute care patient portals: recommendations on utility and use from six early adopters. J Am Med Inform Assoc 2018 Apr 1;25(4):370-379. [doi: 10.1093/jamia/ocx074] [Medline: 29040634]

14. Kelly MM, Dean SM, Carayon P, Wetterneck TB, Hoonakker PL. Healthcare team perceptions of a portal for parents of hospitalized children before and after implementation. Appl Clin Inform 2017 Dec 15;8(1):265-278 [FREE Full text] [doi: 10.4338/ACI-2016-11-RA-0194] [Medline: 28293685]

15. Griffin A, Skinner A, Thornhill J, Weinberger M. Patient portals: who uses them? What features do they use? And do they reduce hospital readmissions? Appl Clin Inform 2016;7(2):489-501. [doi: 10.4338/ACI-2016-01-RA-0003] [Medline: 27437056]

16. Tieu L, Schillinger D, Sarkar U, Hoskote M, Hahn KJ, Ratanawongsa N, et al. Online patient websites for electronic health record access among vulnerable populations: portals to nowhere? J Am Med Inform Assoc 2016 Jul 8:e47-e54. [doi: 10.1093/jamia/ocw098] [Medline: 27402138]

17. Tieu L, Sarkar U, Schillinger D, Ralston JD, Ratanawongsa N, Pasick R, et al. Barriers and facilitators to online portal use among patients and caregivers in a safety net health care system: a qualitative study. J Med Internet Res 2015;17(12):e275 [FREE Full text] [doi: 10.2196/jmir.4847] [Medline: 26681155]

\section{Abbreviations}

AOR: adjusted odds ratio

EHR: electronic health record

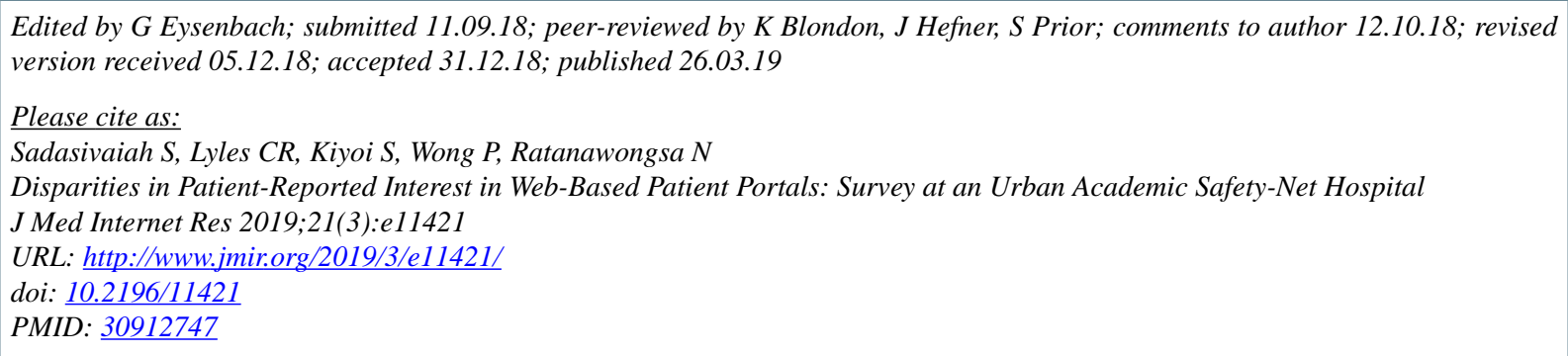


(C) Shobha Sadasivaiah, Courtney R Lyles, Stephen Kiyoi, Piera Wong, Neda Ratanawongsa. Originally published in the Journal of Medical Internet Research (http://www.jmir.org), 26.03.2019. This is an open-access article distributed under the terms of the Creative Commons Attribution License (https://creativecommons.org/licenses/by/4.0/), which permits unrestricted use, distribution, and reproduction in any medium, provided the original work, first published in the Journal of Medical Internet Research, is properly cited. The complete bibliographic information, a link to the original publication on http://www.jmir.org/, as well as this copyright and license information must be included. 